\title{
Interpretation of FRA Results through Low Frequency Transformer Modelling
}

DOI:

10.1109/ICEMPE.2019.8727328

\section{Document Version}

Accepted author manuscript

Link to publication record in Manchester Research Explorer

\section{Citation for published version (APA):}

Cheng, B., Crossley, P., Wang, Z., Jarman, P., \& Fieldsend-roxborough, A. (2019). Interpretation of FRA Results through Low Frequency Transformer Modelling. In 2019 2nd International Conference on Electrical Materials and Power Equipment (ICEMPE) (pp. 592-595) https://doi.org/10.1109/ICEMPE.2019.8727328

\section{Published in:}

2019 2nd International Conference on Electrical Materials and Power Equipment (ICEMPE)

\section{Citing this paper}

Please note that where the full-text provided on Manchester Research Explorer is the Author Accepted Manuscript or Proof version this may differ from the final Published version. If citing, it is advised that you check and use the publisher's definitive version.

\section{General rights}

Copyright and moral rights for the publications made accessible in the Research Explorer are retained by the authors and/or other copyright owners and it is a condition of accessing publications that users recognise and abide by the legal requirements associated with these rights.

\section{Takedown policy}

If you believe that this document breaches copyright please refer to the University of Manchester's Takedown Procedures [http://man.ac.uk/04Y6Bo] or contact uml.scholarlycommunications@manchester.ac.uk providing relevant details, so we can investigate your claim.

\section{OPEN ACCESS}




\title{
Interpretation of FRA Results through Low Frequency Transformer Modelling
}

\author{
Bozhi Cheng ${ }^{1}$, Peter Crossley ${ }^{1}$, Zhongdong Wang ${ }^{1}$, Paul Jarman ${ }^{2}$ and Andrew Fieldsend-Roxborough ${ }^{2}$ \\ ${ }^{1}$ School of Electrical and Electronic Engineering, the University of Manchester, Manchester M13 9PL, UK \\ ${ }^{2}$ National Grid Company, Warwick CV34 6DA, UK
}

\begin{abstract}
Currently there is no standard FRA interpretation methods and not all the FRA practitioners are capable to model transformer windings using equivalent circuits. A low-frequency transformer model of a three-limb core-type 1000 MVA $400 / 275 / 13 \mathrm{kV}$ auto-transformer is established to analyze the effects of transformer electric parameters on the FRA plots. The equivalent electrical circuit of the magnetic core is derived based on the Principle of Duality. Air-core inductance and winding capacitances are included in the model. FRA simulation results are validated by measurement results, the suitability of transformer model is discussed and the dominant factors in different frequency regions are concluded through sensitivity studies.
\end{abstract}

\section{INTRODUCTION}

Condition monitoring and assessment techniques have been widely used by the utilities to manage power transformers. Frequency Response Analysis (FRA) is regarded as the most effective technique to detect winding deformation [1]. By injecting a sinusoidal signal with swept frequency into one terminal of the winding and measuring the output signal at the other terminal of the same winding, an end-to-end FRA response can be obtained [2].

Although the validity and sensitivity of FRA techniques have been proven by experiments [3], no standard FRA interpretation methods have been widely accepted by the community although currently there is a CIGRE working group aiming to produce such a technical brochure.

Transformer windings can be considered as an equivalent electrical circuit of inductances (L) and capacitances (C), and the values of $\mathrm{L}$ and $\mathrm{C}$ are primarily dominated by winding geometry, any mechanical change of winding, movement or deformation, may result in the change of $\mathrm{L}$ and $\mathrm{C}$ and would affect the anti-resonances and resonances of the FRA plots. Based on transformer modeling, it is generally known that the FRA response from low to high frequencies can be dominated by the core, the interaction between windings, the structure of the winding-under-test and the measurement connection leads, however, not all the FRA practitioners are capable of modelling due to the lack of modelling tools and there is a need to analyse the effects of transformer electric parameters on the FRA plots.

In this paper, the FRA characteristics of a three-limb 1000 MVA 400/275/13 kV transformer are investigated through a low frequency transformer model, the suitability of the model is discussed through the comparison between simulation and measurement results, the effects of transformer electric parameters on the winding FRA responses are analysed in terms of key parameters and their dominating frequency regions.

\section{SIMULAION MODEL}

\section{A. Modelling}

A typical UK three-phase 1000MVA 400/275/13 kV autotransformer is modelled [4], and the model is built in MULTISIM. The schematic drawing of A phase windings is presented in Fig 1, where the series winding is of interleaved disc type with a central entry, the common winding is of intershielded disc type and the tertiary winding helical winding type. Fig 2 shows three-phase winding connections and terminal notations, it can be noted that neutral terminals $(\mathrm{Na}, \mathrm{Nb}$ and $\mathrm{Nc}$ ) of the three phases are separately brought out and the delta connection of three phase tertiary windings can be set to closed or open condition by connecting $3 \mathrm{~A} 2$ with 3B1 or not.

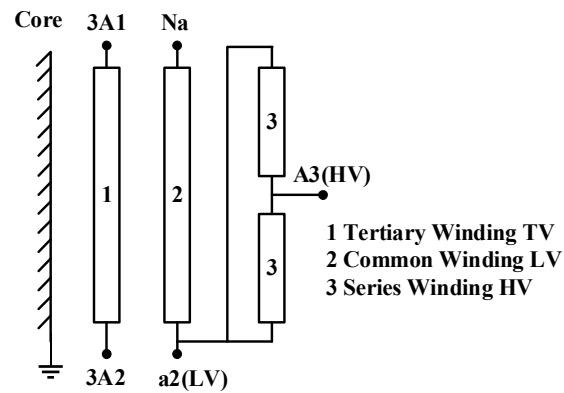

Fig 1 Construction of A phase winding set of 1000 MVA 400/275/13 kV autotransformer
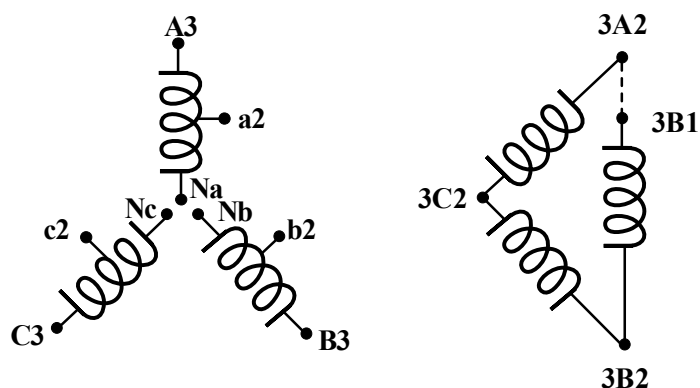

Fig 2 Three phase winding connections of 1000 MVA 400/275/13 kV autotransformer 
Magnetic core is modelled according to the principle of duality. An equivalent circuit involving both inductive and capacitive elements is established as shown in Fig 3. Nine ideal transformers split the inductive part including core and leakage from the winding part represented by capacitive elements of the model. For the transformer core, core leg and core yoke inductances are represented by $\mathrm{L}_{\mathrm{LEG}}$ and $\mathrm{L}_{\mathrm{YOKE}}$, they both can be derived from transformer open-circuit tests [5]. $\mathrm{L}_{\mathrm{S}}, \mathrm{L}_{\mathrm{C}}$ and $\mathrm{L}_{\mathrm{T}}$ represent the air-core inductance of series, common and tertiary winding respectively, which can be calculated based on transformer manufacture data sheet [4]. All the representations of capacitance symbols can be found as given in TABLE 1; the ground capacitances and the interwinding capacitance between common and tertiary windings can be measured based on capacitance tests $[4,5]$ or calculated based on manufacture data sheet $[4,5]$, whilst the series capacitances and the interwinding capacitance between common and series windings can only be calculated based on manufacture data sheet [4].

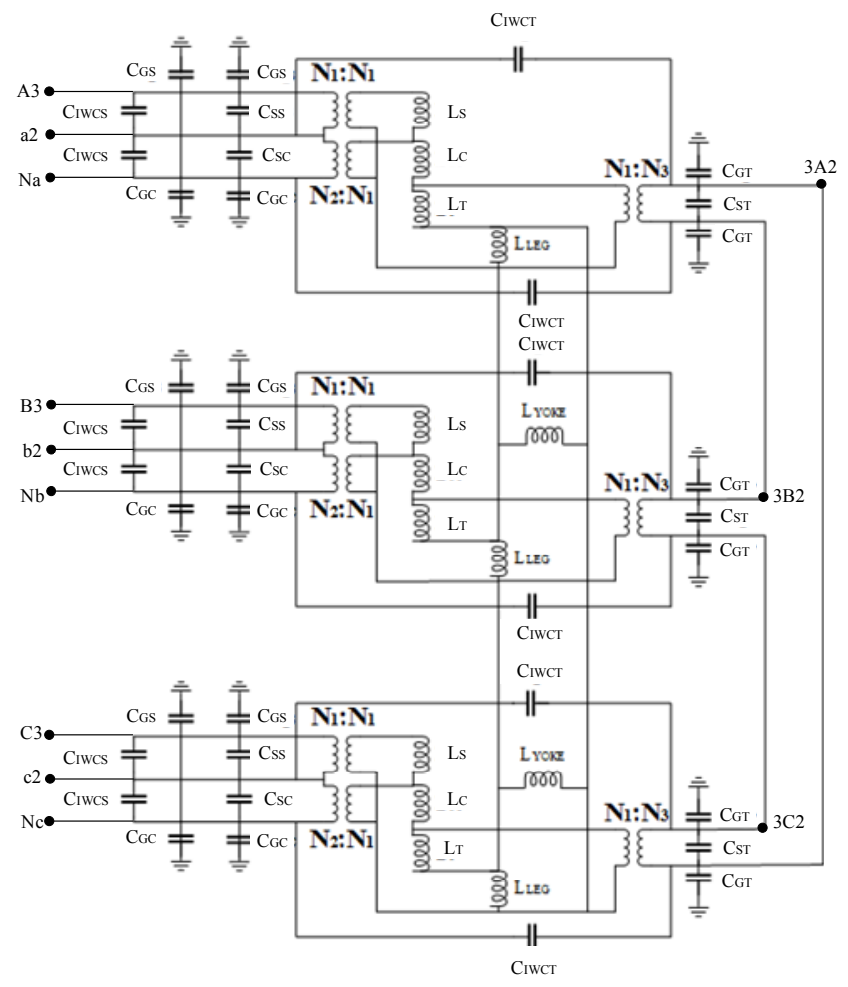

Fig 3 Model of 1000 MVA 400/275/13 kV auto-transformer

TABLE 1 shows the corresponding electrical parameters used in the model, note that all core leg and core yoke inductances and the air core inductances are the values referred to the side of series winding.

A general observation on the values of parameters in TABLE 1 can be made as follows: the series winding has the largest winding series capacitance value than that of common and tertiary windings due to the design requirement to withstand lightning impulse; and the air core inductances are geometry related but mainly dominated by the turn number of winding.
TABle 1 Capacitance AND Inductance Parameters IN THE Model

\begin{tabular}{|c|c|}
\hline Parameters & Values \\
\hline Ground capacitance of series winding $\mathrm{C}_{\mathrm{GS}}$ & $241.08 \mathrm{pF}$ \\
\hline Series capacitance of series winding $\mathrm{C}_{\mathrm{SS}}$ & $1603.86 \mathrm{pF}$ \\
\hline Ground capacitance of common winding $\mathrm{C}_{\mathrm{GC}}$ & $38.5 \mathrm{pF}$ \\
\hline Series capacitance of common winding $\mathrm{C}_{\mathrm{SC}}$ & $30.21 \mathrm{pF}$ \\
\hline $\begin{array}{c}\text { Interwinding capacitance between common and series } \\
\text { windings } \mathrm{C}_{\mathrm{IWCS}}\end{array}$ & $1495.57 \mathrm{pF}$ \\
\hline Ground capacitance of tertiary winding $\mathrm{C}_{\mathrm{GT}}$ & $2820.05 \mathrm{pF}$ \\
\hline Series capacitance of tertiary winding $\mathrm{C}_{\mathrm{ST}}$ & $5.67 \mathrm{pF}$ \\
\hline $\begin{array}{c}\text { Interwinding capacitance between common and tertiary } \\
\text { windings } \mathrm{C}_{\mathrm{IWCT}}\end{array}$ & $772.45 \mathrm{pF}$ \\
\hline Air-core inductance of series winding $\mathrm{L}_{\mathrm{S}}$ & $159.2 \mathrm{mH}$ \\
\hline Air-core inductance of common winding $\mathrm{L}_{\mathrm{C}}$ & $83.34 \mathrm{mH}$ \\
\hline Air-core inductance of tertiary winding $\mathrm{L}_{\mathrm{T}}$ & $438.51 \mathrm{mH}$ \\
\hline Core leg inductance $\mathrm{L}_{\mathrm{LEG}}$ & $13.43 \mathrm{H}$ \\
\hline Core yoke inductance $\mathrm{L}_{\mathrm{YOKE}}$ & $12.61 \mathrm{H}$ \\
\hline$N_{1}: N_{2}$ & $125: 275$ \\
\hline$N_{1}: N_{3}$ & $125 / \sqrt{3}: 13$ \\
\hline
\end{tabular}

\section{B. Model Validation}

In order to validate the model, a comparison between FRA measurement and simulation results is presented up to $1 \mathrm{MHz}$. The three phase FRA responses of series winding, common winding and tertiary winding are presented in Fig 4, Fig 5 and Fig 6 respectively. In each Fig the top plot is for measurement and the bottom the simulation results.

It should be noted that terminal connections may affect the FRA responses. For series winding and common winding FRA tests, the delta connection of tertiary windings was set to be closed, all the non-tested terminals were left floating except that the neutrals of the non-tested phases were earthed; for the tertiary winding FRA tests, the non-tested winding terminals were left floating except that the three phase neutrals were earthed.

The frequencies of anti-resonances and resonances of both measurement and simulation results are presented on the FRA responses. For FRA measurement results, in the low frequency region, the transformer winding-under-test behaves as an inductive element because of large core inductance, consequently FRA responses have a decreasing trend of $20 \mathrm{~dB} /$ decade; as the frequency increases, the inductances and winding capacitances start to have resonant coupling effect and anti-resonances, showing themselves as local minimums, appear on the FRA responses, due to the different length of flux path, $\mathrm{A}$ and $\mathrm{C}$ phase windings have two anti-resonances whilst $\mathrm{B}$ phase windings have only one anti-resonance. As the frequency keeps increasing, a typical double-peck feature (two resonances) from $2.75 \mathrm{kHz}$ to $9.65 \mathrm{kHz}$ can be found on the FRA responses of both series and common windings. In the high frequency region, FRA responses of series windings follow an increasing trend with almost no oscillations due to the large series capacitance, and with small series 
capacitances, multiple resonances and anti-resonances can be found on FRA responses of common and tertiary windings.

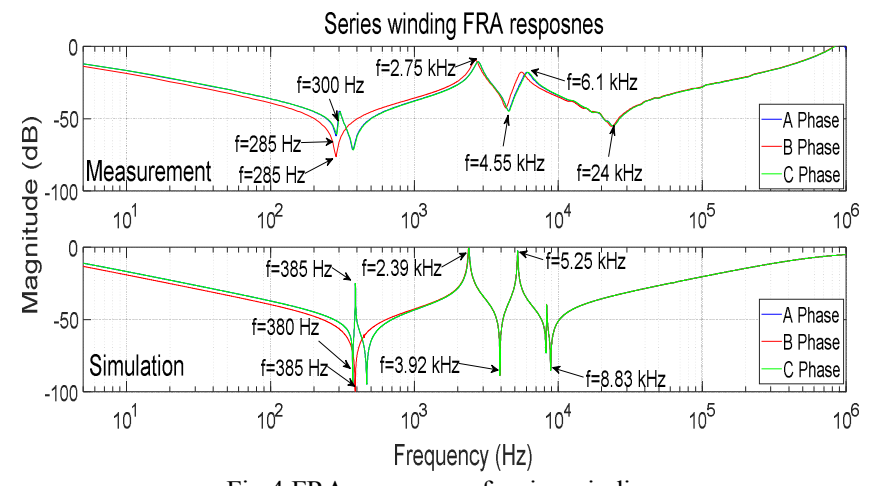

Fig 4 FRA responses of series winding

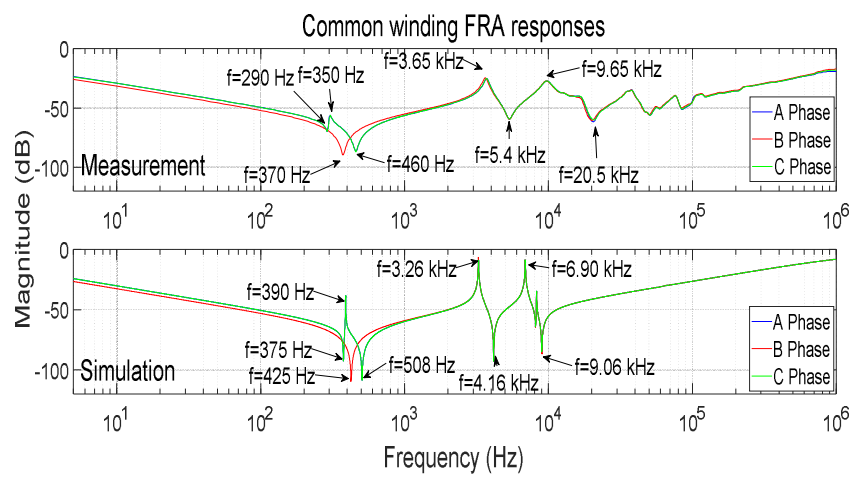

Fig 5 FRA responses of common winding

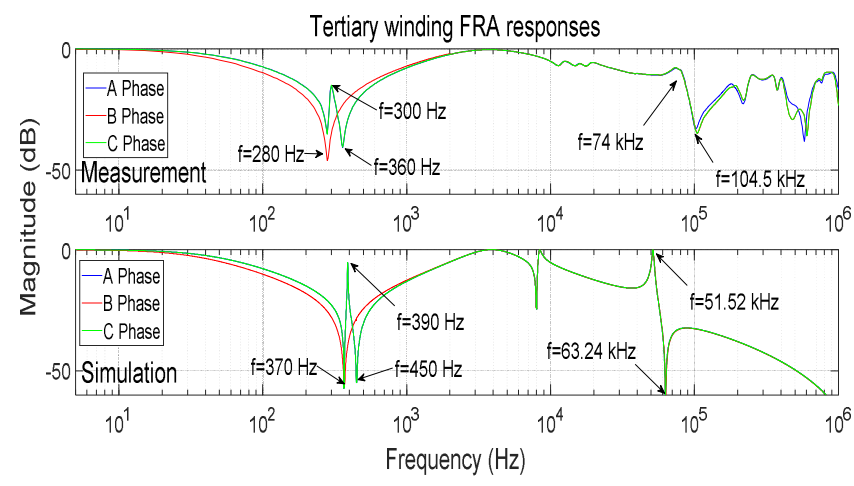

Fig 6 FRA responses of tertiary winding

Comparing the simulation with the measurement results, although the resonances and anti-resonances cannot match perfectly, the simulation results show reasonable trends especially at the low frequency region, as the anti-resonances created by core inductance and winding capacitances and the double-peak features can be clearly represented by the model. Because the model is merely a one-order model (a winding branch is represented as one winding series capacitance and one air core inductance), the over-simplicity of the winding part deems itself not suitable to represent the multiple resonances in high frequencies. This is particularly true for the FRA responses of common and tertiary windings, as they both have small winding series capacitance values, consequently the inductance can still couple with winding series capacitance in the high frequency region, and therefore needs detailed model to reproduce the multiple resonance features.

\section{SENSITIVITY STUDIES}

A sensitivity study on electric parameters in TABLE 1 is implemented to identify their effects on FRA anti-resonant and resonant frequencies. For simplicity B phase series winding is chosen as an example for this study. Electric parameters of the equivalent circuit are changed to firstly $50 \%$ and then $200 \%$ of the original values, and the FRA responses are plotted to compare. It should be noted that parameter changes are made on all three phases, also in the sensitivity studies the frequency shifts, $\Delta \mathrm{f}$ have been indicated in the Figs rather than the anti-resonant or resonant frequency.

Fig 7 shows the FRA responses of B phase series winding before and after the inductive parameters are changed. Firstly our previous understanding is confirmed that the first antiresonance is dominated by the core inductance, and the core has no influence on the double peak features, i.e. their resonant frequencies, secondly the effects of air core inductances of the three windings on B phase series winding FRA response are varied; the air-core inductances of series and common windings produce significant impact on the double-peak feature, whilst the air-core inductance of tertiary winding can hardly make any impact.
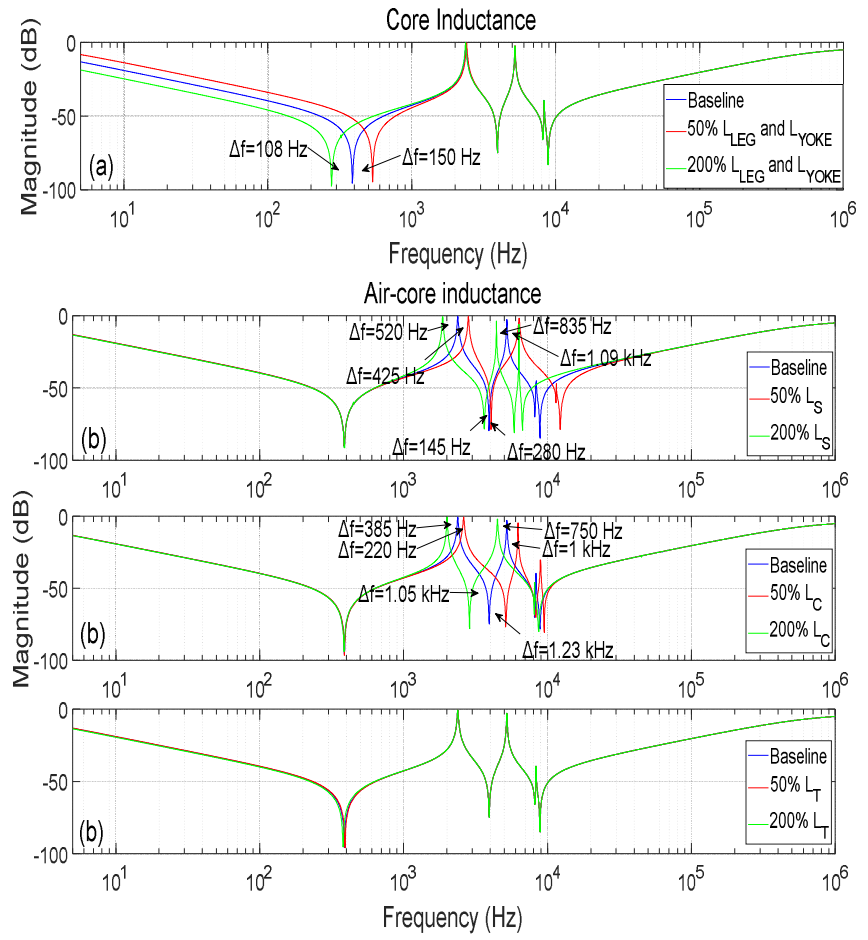

Fig 7 Effect of inductive parameters on FRA response of B phase series winding

The effects of capacitive parameters on the FRA response of $\mathrm{B}$ phase series winding as presented in Fig 8 can be split into three sub-groups according to the influential degree of each 
parameter. In the first sub-group hardly any change can be observed on the B phase series winding FRA response, neither the anti-resonance nor the resonance frequencies have been shifted with the change of series and ground capacitances of common and tertiary windings. In the second sub-group the ground $\left(\mathrm{C}_{\mathrm{GS}}\right)$ and series capacitances $\left(\mathrm{C}_{\mathrm{SS}}\right)$ of series winding can impact both the first anti-resonance and double peak features, and $\mathrm{C}_{\mathrm{SS}}$ can even affect the magnitude of FRA curve in the high frequency region.
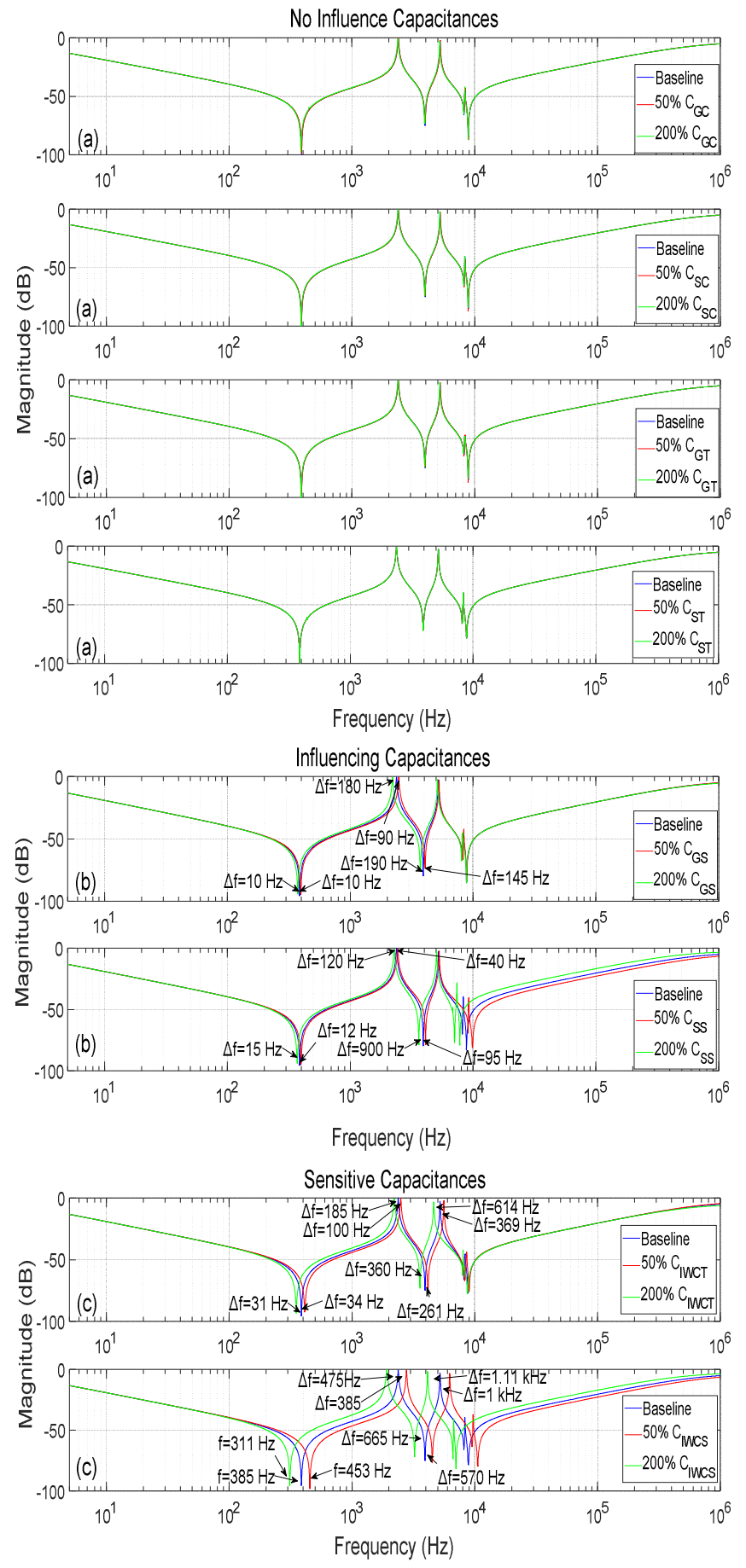

Fig 8 FRA responses of capacitive parameters sensitivity studies
In the third sub-group the interwinding capacitaces $\left(\mathrm{C}_{\mathrm{IWCS}}\right.$, $\mathrm{C}_{\text {IWCT }}$ ) can affect the first anti-resonance and double peak features to some sensitive extend, and $\mathrm{C}_{\mathrm{IWCS}}$ is the most dominant factor. The shifting of the first anti-resonance frequency can be used to estimate the relationship between the equivalent capacitance $\mathrm{C}_{\mathrm{e}}$ and $\mathrm{C}_{\mathrm{IWCS}}$ by using $f=\frac{1}{2 \pi \sqrt{L C_{e}}}$, $\mathrm{L}$ is the inductance seen from $B$ phase series winding, and it equals to $7 \mathrm{H}$, after reducing $50 \%$ of $\mathrm{C}_{\text {IWCS }}$, the frequency of the first anti-resonance shifted to the right from $385 \mathrm{~Hz}$ to $453 \mathrm{~Hz}$, and $\mathrm{C}_{\mathrm{e}}$ decreases from $23918 \mathrm{pF}$ to $17276 \mathrm{pF}$; after increasing $100 \%$ of $\mathrm{C}_{\text {IWCS }}$, the frequency of first anti-resonance shifted to left from $385 \mathrm{~Hz}$ to $311 \mathrm{~Hz}$, and $\mathrm{C}_{\mathrm{e}}$ increases from $23918 \mathrm{pF}$ to $36654 \mathrm{pF}$, consequently it can be derived that the equivalent capacitance $\mathrm{C}_{e}$ of the first anti-resonance follows a linear relationship with the interwinding capacitance $\mathrm{C}_{\mathrm{IWCS}}$, as given by $\mathrm{C}_{\mathrm{e}}=\left(4.31 \mathrm{C}_{\mathrm{IWCS}}+10908\right) \mathrm{pF}$.

\section{CONCLUSION}

In this paper, a low frequency transformer model is established to produce FRA simulation results, the simulation results are verified by comparing with measurement results, it can be concluded that the model is able to produce reasonable FRA curves in the low frequency region, the anti-resonances and double peak feature can be simulated, however, due to the simplicity of the model, the multiple resonant couplings in the high frequency cannot be represented. Hence a more detailed transformer model is necessary to help understanding the FRA responses in the whole frequency spectrum.

The influence of electric parameters on FRA response is presented for low frequency features through sensitivity studies, and a first attempt to estimate the relationship between the equivalent capacitance $\mathrm{C}_{e}$ seen by the first anti-resonance and the interwinding capacitance $\mathrm{C}_{\mathrm{IWCS}}$ is made in this paper.

\section{REFERENCES}

[1] Z. D. Wang, J. Li, and D. M. Sofian, "Interpretation of Transformer FRA Responses-Part I: Influence of Winding Structure," (in English), IEEE Transactions on Power Delivery, vol. 24, no. 2, pp. 703-710, Apr 2009.

[2] "IEEE Guide for the Application and Interpretation of Frequency Response Analysis for Oil-Immersed Transformers," IEEE Std C57.1492012, pp. 1-72, 2013.

[3] M. H. Samimi, S. Tenbohlen, A. A. S. Akmal, and H. Mohseni, "Effect of Different Connection Schemes, Terminating Resistors and Measurement Impedances on the Sensitivity of the FRA Method," (in English), IEEE Transactions on Power Delivery, vol. 32, no. 4, pp. 1713-1720, Aug 2017.

[4] A. Swee Peng, L. Jie, W. Zhongdong, and P. Jarman, "FRA low frequency characteristic study using duality transformer core modeling," in 2008 International Conference on Condition Monitoring and Diagnosis, 2008, pp. 889-893.

[5] D. A. K. Pham, T. M. T. Pham, H. Borsi, and E. Gockenbach, "A new method for purposes of failure diagnostics and FRA interpretation applicable to power transformers," IEEE Transactions on Dielectrics and Electrical Insulation, vol. 20, no. 6, pp. 2026-2034, 2013. 